\title{
Sediment-induced buoyancy destruction and drag reduction in estuaries
}

\author{
Johan C. Winterwerp • Marieke Lely • Qing He
}

Received: 14 November 2008 / Accepted: 16 September 2009/Published online: 10 October 2009

(C) The Author(s) 2009. This article is published with open access at Springerlink.com

\begin{abstract}
This paper presents an analysis of drag reduction by buoyancy destruction in sediment-laden open channel flow. We start from the log-linear profile proposed by Barenblatt (Prikladnaja Matematika i Mekhanika, 17:261274, 1953), extended with a second length scale to account for free surface effects. Upon analytical integration over the water depth, an expression for sediment-induced drag reduction is found in terms of an effective Chézy number, water depth, bulk Richardson number, and Rouse number. This relation contains one empirical/experimental coefficient, which was obtained from a large series of numerical experiments with a 1DV POINT MODEL. Upon calibration of this model against field and laboratory observations, we tuned the turbulent Prandtl-Schmidt number and found an optimal value of $\sigma_{\mathrm{T}}=2$, consistent to observations by Cellino and Graf (ASCE, J Hydraulic Engineering, 125:456-462, 1999). All numerical results could be correlated with the
\end{abstract}

Responsible Editor: Roger Proctor

J. C. Winterwerp · M. Lely

Environmental Fluid Mechanics, Delft University of Technology,

P.O. Box 5048, 2600 GA Delft, The Netherlands

M. Lely

e-mail: Marieke.Lely@mtbs.nl

J. C. Winterwerp $(\bowtie)$

Deltares (formerly WL|Delft Hydraulics),

P.O. Box 177, $2600 \mathrm{MH}$ Delft, The Netherlands

e-mail: j.c.winterwerp@citg.tudelft.nl

e-mail: han.winterwerp@deltares.nl

Q. He

State Key Laboratory of Estuarine and Coastal Research,

East China Normal University,

No. 3663 Zhongshan Northern Road,

Shanghai 200062, People's Republic of China

e-mail: qinghe@sklec.ecnu.edu.cn simple relation $C_{\text {eff }}=C_{0}+4 \sqrt{g} h R i_{*} \beta$, which is valid for fine sediment suspensions under conditions typical in open channel flow.

Keywords Fine suspended sediment · Buoyancy destruction · Drag reduction · Yangtze

\section{Introduction}

Many observations have been reported in the literature on drag reduction by suspended fine sediments in rivers and estuaries. For instance, Dong et al. (1997) and Guan et al. (1998) reported decreases in bed friction by about $15 \%$ in the JiaoJiang estuary, China; Wang et al. (1998) found drag reductions of $15-30 \%$ in the Yellow River; Beardsley et al. (1995) and Gabioux et al. (2005) found drag reductions in the Amazon mouth in the range of $25 \%$, similar to values reported in the Yangtze River (Port and Delta Consortium Ltd. 1995). Also in Europe, comparable reductions were found in the Ems estuary, Germany/The Netherlands (Weilbeer 2005), in the Loire estuary, France (Le Hir 1994; Le Hir and Cayocca 2002), and in the Severn estuary, UK (Odd and Cooper 1988), to name a few.

From theoretical considerations, drag reduction by fine sediments may be explained from four processes, assuming that a one-phase description of the sediment-water mixture is valid:

1. buoyancy destruction induced by vertical gradients in suspended sediment concentration,

2. turbulence damping by fluid mud formation,

3. reduction in bed forms; hence reduction in form drag, and

4. thickening of the viscous sub-layer through viscous damping induced by mud flocs. 
The latter was studied experimentally by Gust (1976) in a small flume with dilute clay suspensions (solids fractions $<1 \%$ ). At hydraulically smooth conditions, drag reductions of about $40 \%$ were observed, which were attributed to a thickening of the viscous sub-layer by a factor $2-5$. Note that Gust did not measure any changes in the velocity profile or turbulence characteristics further away from the wall. In fact, the logarithmic law still appears applicable, with the common values of the Von Kármàn constant (i.e., $\kappa=0.4$ ). Gust hypothesized that this drag reduction is caused by the streamlining of deformable mud flocs, similar to drag reduction by polymers (Lumley 1969).

The generation of bedforms is generally attributed to bed load transport; in fact, all bedform models use bed load formulae to predict bed form dimensions (e.g., Van Rijn 1993). However, bed load transport is not likely in environments with fine sediment suspensions (apart from special features such as fluid mud, which are beyond the subject of the current paper). Therefore, one would expect general absence of bed forms in flows laden with fine sediment. Yet, it is known that bed forms in muddy environments can develop, such as the ridges and runnels developing in streamwise direction in the Bay of Marenne (Dyer 1997).

Locally, drag reduction by fluid mud most likely plays a role in the mouth of the Amazon River and in the Ems and Loire. However, under normal conditions, fluid mud does not occur on a large scale in the Yangtze channels.

At present, it is not known whether all four mechanisms contribute to drag reduction in fine sediment-laden flows, or whether under specific conditions one or the other is dominant. In the current paper, we analyze the contribution of sediment-induced buoyancy destruction on drag reduction. This analysis is carried out through sensitivity analyses with a numerical model, assessing hydraulic drag through numerical simulations with and without suspended fine sediment. Currently, the effects of buoyancy destruction are well understood, and may be modeled properly in three-dimensional numerical models with a $k-\varepsilon$ turbulence closure scheme (e.g., Winterwerp 2001). However, as such models still require considerable computational efforts, we first parameterize the effects of buoyancy destruction through a formal integration of Barenblatt (1953) log-linear velocity profile. The coefficient that emerges in this model is established with a 1DV POINT MODEL (1DV MODEL; e.g., Winterwerp 2001) which was developed through stripping all horizontal gradients, except the horizontal pressure gradient, from the three-dimensional numerical Delft3D code. This model accounts for buoyancy destruction in the $k-\varepsilon$ turbulence closure equation through inclusion of the suspended sediment concentration in the equation of state.

This approach has an additional advantage in deriving an (implicit) formulation of the effect of buoyancy destruction on hydraulic drag. This formulation can be used for analysis of laboratory or field data, and/or in depthaveraged numerical models, which, of course, cannot account for these effects explicitly.

\section{The log-linear velocity profile}

Barenblatt (1953) was most likely the first to elaborate on the effects of buoyancy destruction on vertical velocity profiles in open channel flow. He developed the famous log-linear velocity profile (Eq. (1)), which is based on the Monin-Obukhov length scale, derived for the atmospheric boundary layer.

$\frac{u}{u_{*}}=\frac{1}{\kappa}\left[\ln \left(\frac{z}{z_{0}}\right)+\alpha_{1}\left(\frac{z}{\ell}\right)\right]$

where $u=$ flow velocity, $u_{*}=$ shear velocity, $\kappa=$ Von Kármàn constant, $z=$ vertical coordinate, and $z_{0}=$ roughness height for neutral conditions. The Monin-Obukhov length scale $\ell \equiv \rho_{\mathrm{b}} u_{*}^{3} / \kappa g \overline{\rho^{\prime} w^{\prime}}$, in which $\rho_{\mathrm{b}}$ is the bulk density of the fluid, $\kappa$ the Von Karman constant, $g$ acceleration of gravity, $\rho^{\prime}$ and $w^{\prime}$ are the turbulent fluctuations of density and vertical velocity, and $\ell$ can be regarded as the height above the earth surface (river bed) where turbulent mixing and buoyancy destruction are in equilibrium. On the basis of experimental data, the coefficient $\alpha_{1}$ attains a value of about 5 (e.g., Turner 1973). However, the length scale $\ell$ does not account for the effects of the free water surface, as in open channel flows, which cause a decrease in mixing length, hence eddy diffusivity towards the water surface, as sketched in Fig. 1. As a result, sediment-induced stratification effects in open water flows are always initiated near the water surface, as was shown conclusively by Soulsby and Wainwright (1987). Therefore, we propose a slight modification of Barenblatt's log-linear profile:

$\frac{u}{u_{*}}=\frac{1}{\kappa}\left[\ln \left(\frac{z}{z_{0}}\right)+\alpha_{2}\left(\frac{z}{\ell} \frac{z}{h_{\mathrm{ref}}}\right)\right]$

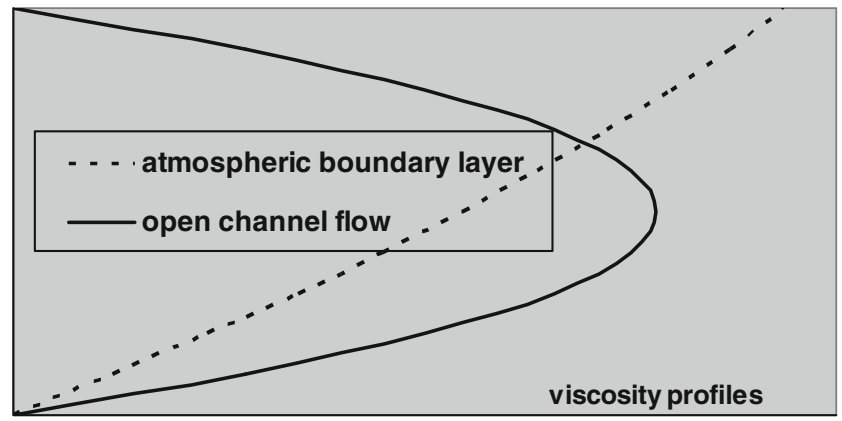

Fig. 1 Schematic eddy viscosity profile in the atmosphere and in open channel flow 
in which we introduce a reference length scale $h_{\text {ref }}$, to be defined later. Integration of the log-parabolic profile (2) over the water depth $h$ yields:

$$
\begin{aligned}
\frac{\bar{u}}{u_{*}}=\frac{C_{\mathrm{eff}}}{\sqrt{g}}=\frac{C_{0}}{\sqrt{g}} & +\frac{C_{\mathrm{SPM}}}{\sqrt{g}}=\frac{1}{\kappa}\left[\ln \left\{\frac{h}{z_{0}}\right\}-1\right] \\
& +K_{1} h \frac{g h\left(\rho_{\mathrm{b}}-\rho_{\mathrm{w}}\right)}{\rho_{\mathrm{b}} u_{*}^{2}} \frac{\sigma_{\mathrm{T}} W_{\mathrm{s}}}{\kappa u_{*}}=\frac{C_{0}}{\sqrt{g}}+K_{1} h R i_{*} \beta
\end{aligned}
$$

where $\rho_{\mathrm{w}}$ is the specific density of water, $C_{\text {eff }}=$ the effective Chézy coefficient, $C_{0}$ is the Chézy coefficient for neutral conditions, $C_{\mathrm{SPM}}$ is the contribution of suspended fine sediment (SPM) to the Chézy coefficient, and $R i *$ and $\beta$ are a bulk Richardson number and the Rouse number, respectively, as defined in Eq. (4). Details of this integration are given in Appendix 1.

$R i_{*} \equiv \frac{\left(\rho_{\mathrm{b}}-\rho_{\mathrm{w}}\right) g h}{\rho_{\mathrm{b}} u_{*}^{2}}$ and $\beta \equiv \frac{\sigma_{\mathrm{T}} W_{\mathrm{s}}}{\kappa u_{*}}$

The turbulent Prandtl-Schmidt number $\sigma_{\mathrm{T}}$ depicts the efficiency of vertical mixing, i.e., $\sigma_{\mathrm{T}}$ is the ratio between the vertical turbulent transport of momentum and matter (ratio of eddy viscosity and eddy diffusivity). The empirical/numerical integration coefficient $K_{1}$ is determined in Section 4 through a large number of numerical experiments with the 1DV POINT MODEL, which accounts for sediment-induced buoyancy effects on the turbulent flow properties. As such, $K_{1}$ implicitly includes the reference length $h_{\text {ref }}$.

Inspection of Eqs. (1) and (2) reveals serious scale effects in small-scale laboratory facilities. The vertical coordinate $z$ will never attain large values, as $z$ is limited by the water depth. This implies that, in small-scale facilities, the logarithmic part of these equations is always much larger than their linear part, hence sediment-induced buoyancy destruction will not easily be observed in such small facilities. This may be one reason why the effects of water depth on vertical velocity profiles in inhomogeneous flows have not been acknowledged before.

\section{Calibration of the 1DV POINT MODEL}

In this study, we use the 1DV POINT MODEL, which is based on the Delft3D software system, stripping all horizontal gradients, except for the horizontal pressure gradient. The 1DV POINT MODEL assumes a hydrostatic pressure distribution and includes:

- the momentum equation,

- balance equations for water and suspended sediment,
- the standard $k-\varepsilon$ turbulence model with buoyancy destruction,

- the equation of state.

Delft3D has been applied extensively for stratified flow problems, including the current $k-\varepsilon$ turbulence model implementation and preferred parameter settings. These applications include stratification by gradients in temperature and salinity. Furthermore, the $k-\varepsilon$ implementation has been evaluated in detail against two-layer experiments in a tidal flume, e.g., Uittenbogaard (1995a, b). Moreover, for homogeneous conditions, Delft3D and the 1DV MODEL reproduce the analytical logarithmic velocity and parabolic viscosity profile; also, the analytical Rouse profile for small concentrations (i.e., when buoyancy effects are not yet large) is reproduced exactly. Yet, one must realize that the results presented in this paper have been obtained with one particular implementation of the governing equations, and we do not claim universal validity of the coefficients obtained (such as the preferred Prandtl-Schmidt numbersee below).

The 1DV POINT MODEL is run by prescribing the (timevarying) water depth, flow rate, and depth-mean suspended sediment concentration, and, if necessary, a vertical profile of salinity. In our simulations, all sediment is kept within the computational domain, i.e., we did not include any water-bed exchange processes. The 1DV POINT MODEL then establishes the vertical profiles of velocity and suspended sediment concentrations, using the set of equations mentioned above. For more information, the reader is referred to Appendix 2 or Winterwerp (2001).

Let us first compare the 1DV POINT MODEL with data on vertical distributions of suspended sediment, as measured in the laboratory and in the field. For this purpose, we refer to Winterwerp (2006) in which the 1DV POINT MODEL has been compared with laboratory data by Cellino and Graf (1999) and with data by $\mathrm{Xu}$ (2003) on the Yellow River and its tributaries, and a large number of irrigation channels. For convenience, we present the relevant graphs again in Figs. 2 and 3. As discussed in Winterwerp (2006), a proper fit between data and the current model, with its specific implementation and parameter settings, can only be achieved when the turbulent Prandtl-Schmidt number is set to $\sigma_{\mathrm{T}}=2$, a value also proposed by Cellino and Graf on the basis of their experimental data.

For stratified, one-phase fluids, the ratio between vertical turbulent momentum and mass transport, the turbulent Prandtl-Schmidt number $\sigma_{\mathrm{T}}$, was found to increase with degree of stratification (Richardson number) in numerous experiments and measurements in the atmosphere, open ocean, and laboratories. Munk and Anderson (1948) were most likely the first proposing an explicit function for the damping of vertical mixing as a function of Richardson 


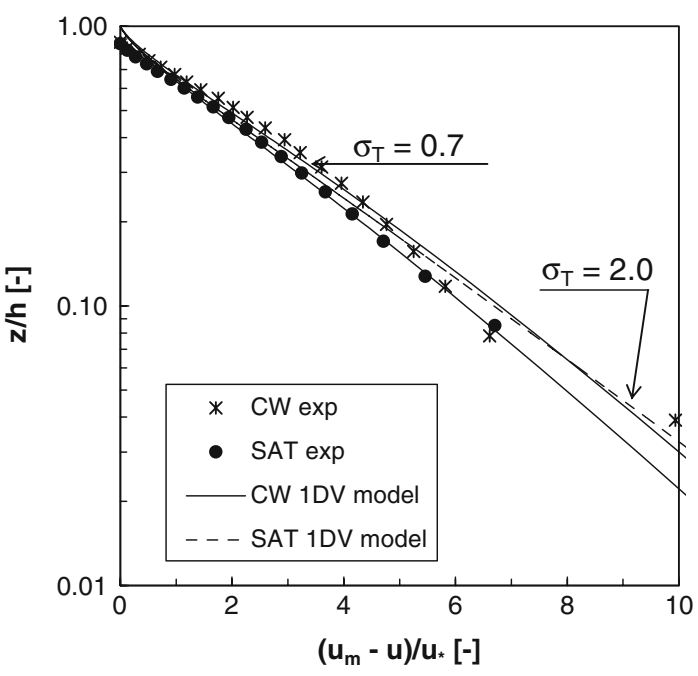

Fig. 2 Comparison of the 1DV POINT MODEL with data measured by Cellino and Graf in a $16.8 \mathrm{~m}$ long and $0.6 \mathrm{~m}$ wide tilting flume. The left panel shows velocity profiles for both clear water and large suspended

number. Delft Hydraulics (1974) gives an overview of the many early relations derived for salinity-induced stratification in open channel flow, whereas Burchard and Baumert (1995) and Burchard (2002) present four more contemporary models. Recently, Toorman (2008) proposed a different approach for sediment-laden flows, relating $\sigma_{\mathrm{T}}$ to the ratio of the particle's settling velocity and the available turbulent kinetic energy. However, currently no consensus exists on modeling of the turbulence properties in sediment-laden flow, mainly because of a lack of data at sufficient detail and at sufficient accuracy. Moreover, applying a Richardson

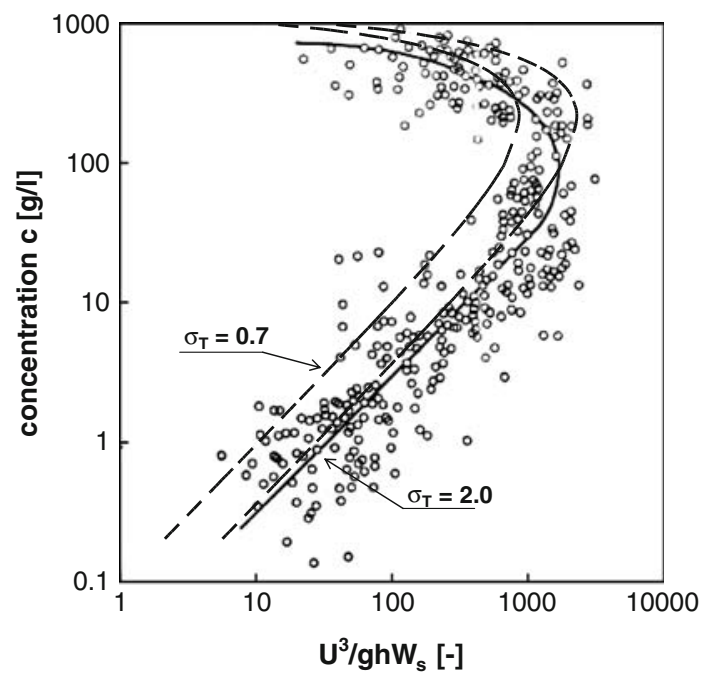

Fig. 3 Comparison of the 1DV POINT MODEL with data by Jiongxin $\mathrm{Xu}$ (2003) in Yellow River, its tributaries, and a number of irrigation channels. A proper agreement between data and model is obtained for $\sigma_{\mathrm{T}}=2$ over the full four decades in suspended sediment concentration

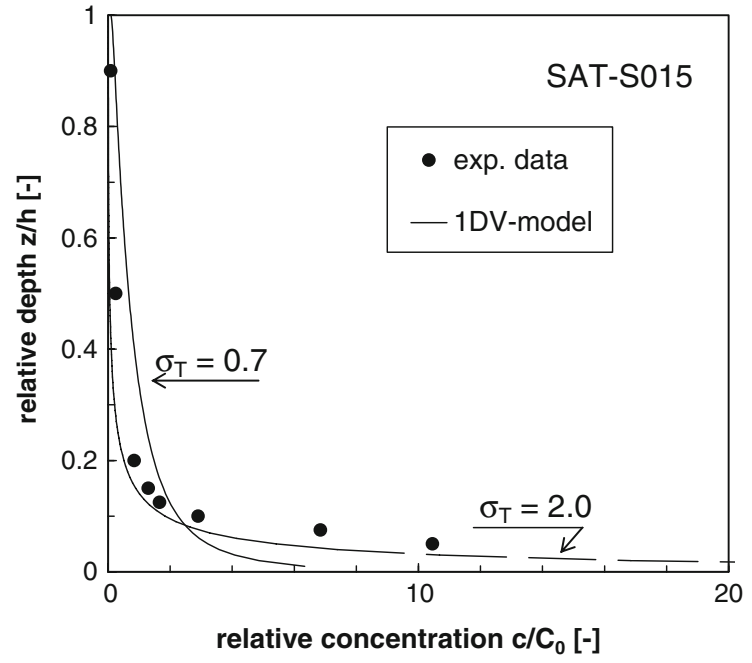

sediment concentrations, and $\sigma_{\mathrm{T}}=0.7$ (standard value for neutral conditions) and $\sigma_{\mathrm{T}}=2$. The effect of $\sigma_{\mathrm{T}}$ on the velocity profiles is not large, but very pronounced on the concentration profiles (right panel)

number-dependent Prandtl-Schmidt number would prohibit analytical integration of Eq. (1) over the water depth, and the subsequent derivation of a simple parameterization for buoyancy-induced drag reduction. Therefore, we will use a constant value for the turbulent Prandtl-Schmidt number, based on the data by Cellino and Graf, and supported by the data presented by Xu (2003).

Next, we apply the 1DV POINT MODEL to Yangtze River conditions. Time series of water depth, flow velocity, salinity, and suspended sediment concentration have been obtained with a tripod anchored on the north side of the South Passage in the Yangtze River mouth (e.g., Fig. 4). Results of these measurements during spring tide on January 11, 2005 are presented in Fig. 5. The river flow was "fairly low" and measured around $12,000 \mathrm{~m}^{3} / \mathrm{s}$. The salinity structure in the Yangtze mouth is characterized by pronounced stratification in the form of a salt wedge, which is manifest throughout the tide, throughout the year (the current river run-off is quite low). Figure 5 shows that the salinity front is advected to and from the tripod location; only around 8:00-10:00 AM the water column contains mainly fresh water, and the suspended sediment concentration is constant as well. Therefore, we analyze the velocity and suspended sediment distribution at 8:00 AM, when horizontal gradients are small. The roughness length is set to $z_{0}=1 \mathrm{~mm}$, after some trial and error, and all sediment is kept in the computational domain (i.e., no sedimentation or erosion). We run the 1DV POINT MODEL both for dynamic conditions, i. e., by prescribing the measured, time-varying water level and flow rate, and for steady-state conditions prescribing the measured water level and flow rate at 8:00 AM. Furthermore, we studied whether the longitudinal salinity gradient of about $0.6 \times 10^{-3} \mathrm{ppt} / \mathrm{m}$ would affect the vertical velocity 
Fig. 4 Yangtze River mouth and location of measurements (tripod)

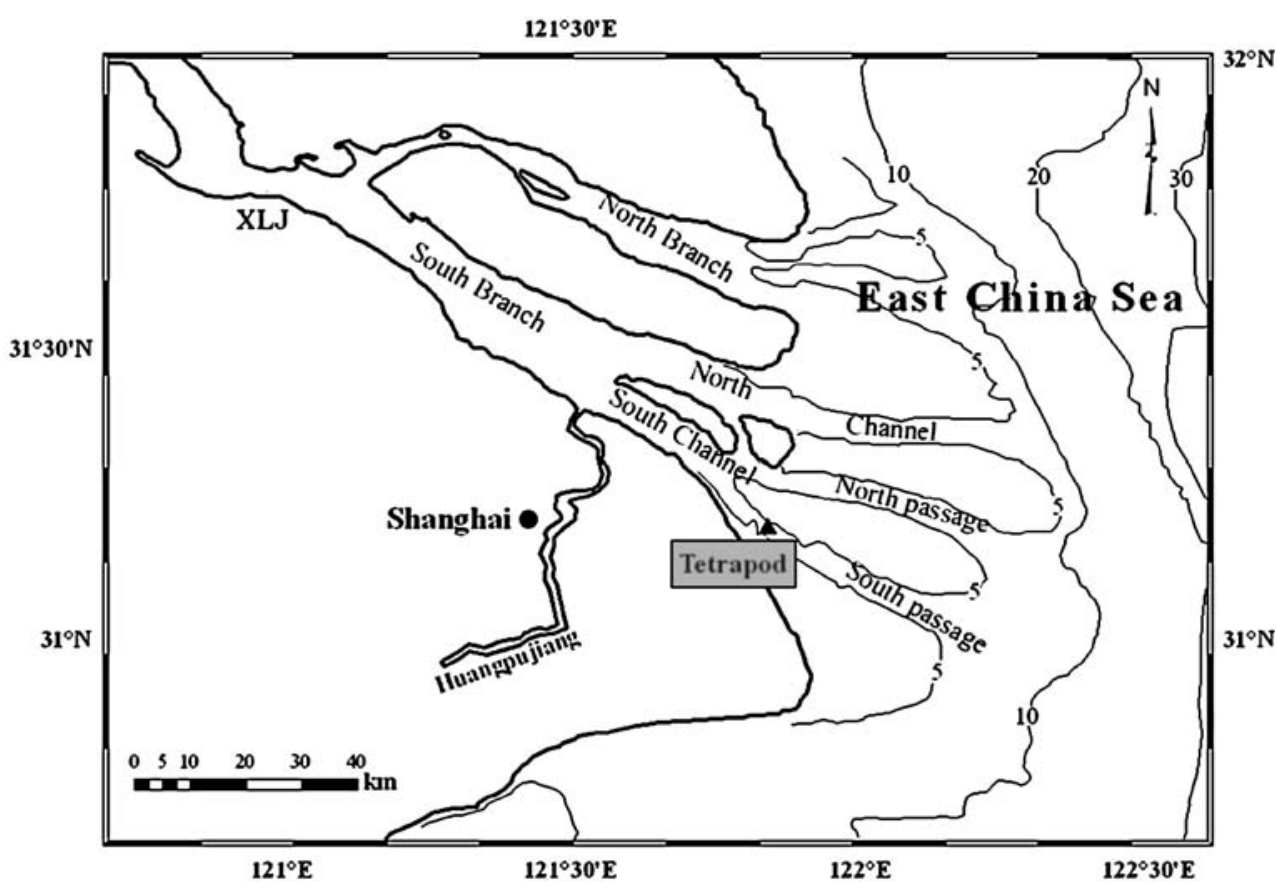

The results of these simulations are presented in Fig. 6 . The majority of the vertical flow profile is reproduced satisfactory (Fig. 6a), except close to the riverbed, where the accuracy of the ADCP measurements is limited by the proximity of the bed. As the velocity profile is quite sensitive to the choice of the roughness coefficient, these simulations are very suitable to calibrate the roughness length. Note that we have included the effects of sedimentinduced buoyancy destruction to account for possible effects of sediment-induced drag reduction, prescribing the

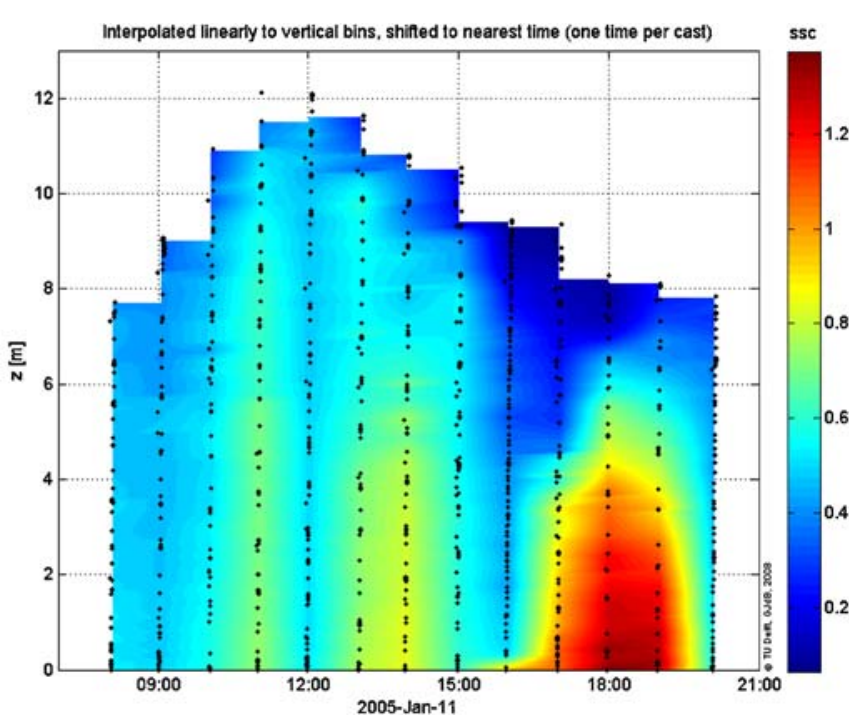

of both $\mathrm{S}$ and $\mathrm{c}$ are negligible- only at this time, application of the 1DV POINT MODEL is meaningful
Fig. 5 Time evolution of measured salinity (left panel) and suspended sediment concentration (right panel) at tripod location (Fig. 4). Note that around 8:00 to 9:00 $\mathrm{h}$ gradients in vertical and horizontal direction

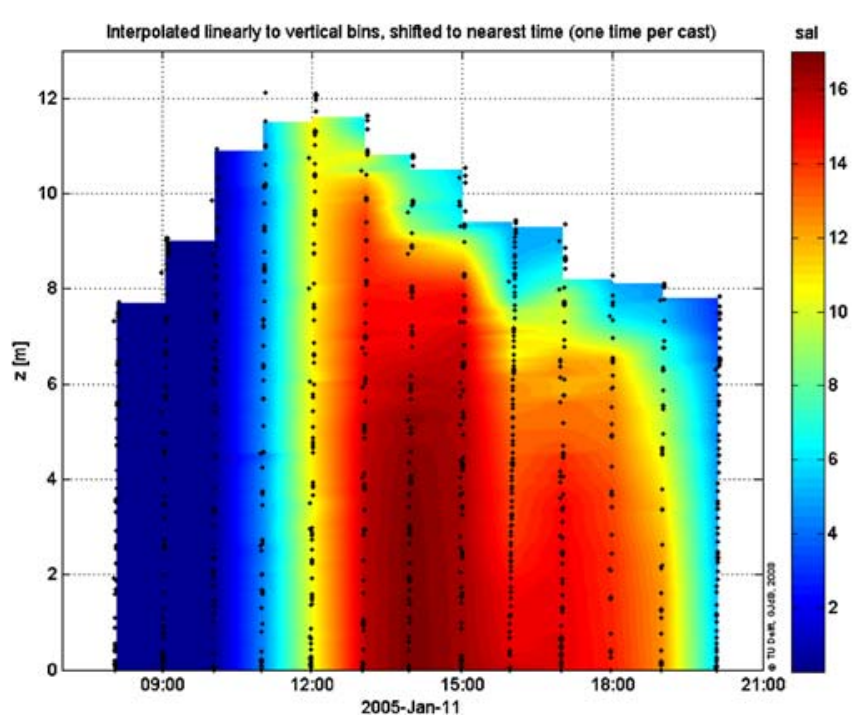

profiles. In all cases, we start the simulations $6 \mathrm{~h}$ earlier,
prescribing water level and flow rate obtained through extrapolation of the observations to allow a proper spin-up flow velocity profile at $8: 00$ AM is not notably afected of simulating the effects of MODEL, the remainder of the simulations has been carried out for the steady-state conditions at 8:00 AM, and without any salinity effects. 


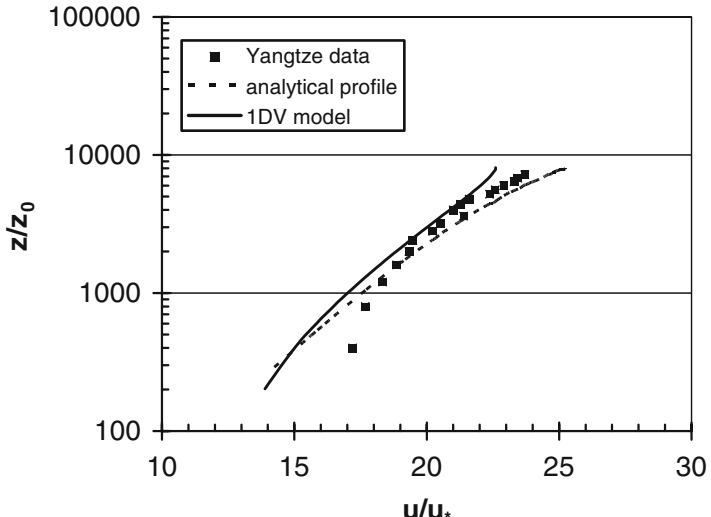

Fig. 6 Comparison of the 1DV POINT MODEL with Yangtze data at 8:00 $\mathrm{h}$. Again, the effect of $\sigma_{\mathrm{T}}$ on the velocity profile is not large, but the measured suspended sediment profile can only be reproduced for

measured depth-mean suspended sediment concentration of $0.476 \mathrm{~g} / \mathrm{l}$. From these simulations, we may conclude that the observed vertical suspended sediment concentrations and sediment transport capacity can only be reproduced properly with the current 1 DV MODEL, if we use a turbulent Prandtl-Schmidt number $\sigma_{\mathrm{T}}=2$ (e.g., Fig. 6b). This implies that vertical transport of momentum in (sediment-induced) stratified flows is more efficient than the vertical mixing of fine suspended sediment.

The three examples discussed in this chapter yield good to fair agreements between observations and IDV SIMULATIONS. This agreement allows us to use the 1DV MODEL in parameterization of sediment-induced drag reduction in open channel flows, at conditions similar to the examples in this chapter.

\section{1DV numerical experiments}

Next, we run the 1DV POINT MODEL for hypothetical open channel flow and stationary conditions. Initially, the water depth was maintained at $h=10 \mathrm{~m}$, but flow velocity (depthmean flow velocity $=0.5<U<2 \mathrm{~m} / \mathrm{s}$ ), roughness height $\left(0.05<z_{0}<1 \mathrm{~mm}\right)$, sediment load (depth-mean suspended sediment concentration $\left.=50<C_{0}<10,000 \mathrm{mg} / \mathrm{l}\right)$, and sediment settling velocity $\left(0.05<W_{\mathrm{s}}<5 \mathrm{~mm} / \mathrm{s}\right)$ were varied extensively. The results of these simulations are presented in Fig. 7 for both $\sigma_{\mathrm{T}}=0.7$ and 2.0. The computational "data" points in Fig. 7 can be represented with $C_{\mathrm{SPM}} / \sqrt{g}=10 R i_{*} \beta$ and $C_{\mathrm{SPM}} / \sqrt{g}=38 R i_{*} \beta$, respectively, for the two Prandtl-Schmidt numbers. This result is again an indication that the larger $\sigma_{\mathrm{T}}$ should be used, as with $\sigma_{\mathrm{T}}=0.7$ we find only very small decreases in hydraulic roughness, whereas $\sigma_{\mathrm{T}}=2.0$ yields reductions up to $30 \%$, consistent with the observations described in Section 1 of this paper.

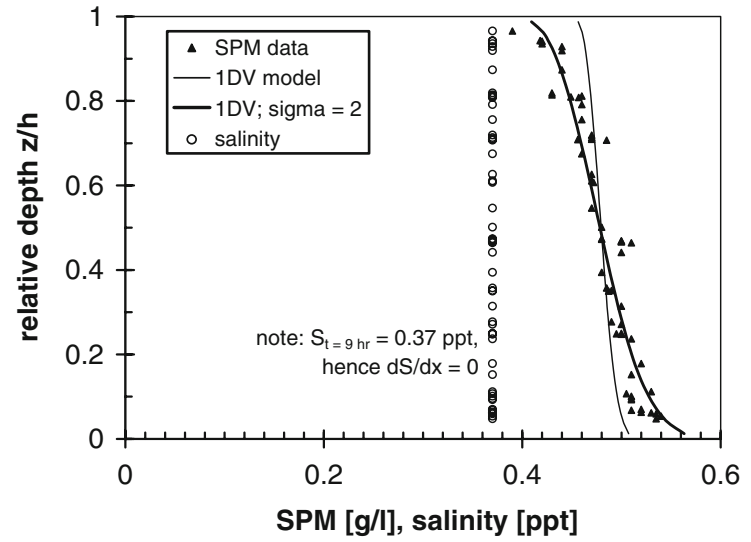

$\sigma_{\mathrm{T}}=2$. To account for spinning up of the model, we have extrapolated the model's boundary conditions to Jan 11, 0:00 h using the measured data

Note that we have not plotted all computational points in Fig. 6; however, we checked that all model results follow the same correlation. The small scatter in the numerical "data" around the linear fit is caused by inaccuracies in reading the numbers from the model output files.

Next, we vary the water depth as well. Figure 8 shows the results when also the water depth is varied between $0.5 \mathrm{~m}$ (results not shown) and $20 \mathrm{~m}$; again, the other parameters were varied as well, as described above, but the Prandtl-Schmidt number was kept constant at $\sigma_{\mathrm{T}}=2.0$. The numerical results can now be correlated by $C_{\mathrm{SPM}} / \sqrt{g}=4 h R i_{*} \beta$. Hence, Eq. (3) becomes:

$\frac{\bar{u}}{u_{*}} \equiv \frac{C_{\mathrm{eff}}}{\sqrt{g}}=\frac{C_{0}}{\sqrt{g}}+\frac{C_{\mathrm{SPM}}}{\sqrt{g}}=\frac{C_{0}}{\sqrt{g}}+4 h R i_{*} \beta$

with the bulk Richardson number and Rouse number defined in Eq. (4).

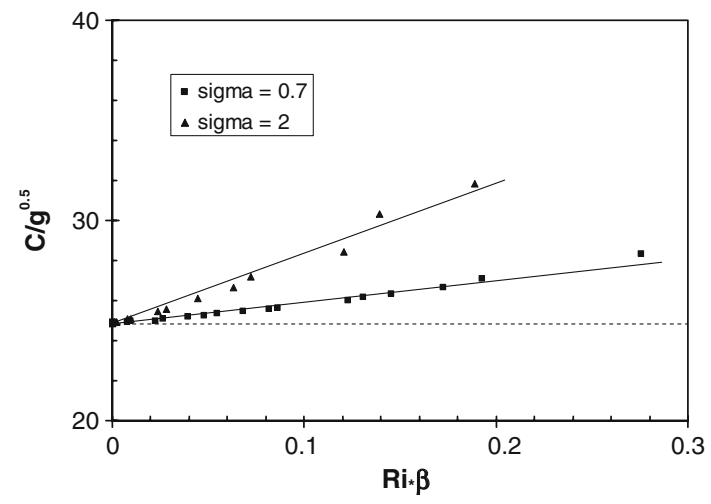

Fig. 7 Numerical experiments with 1DV POINT MODEL, determining drag reduction as a function of $R i_{*} \beta$ for $h=10 \mathrm{~m}$ and $\sigma_{\mathrm{T}}=0.7$ and 2; variation of $U, z_{0}, C_{0}$, and $W_{\mathrm{s}}$ 


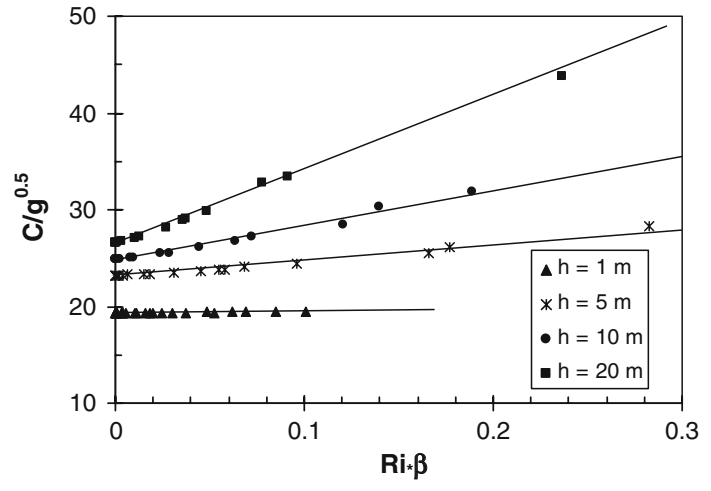

Fig. 8 Numerical experiments with 1DV POINT MODEL, determining drag reduction as a function of $R i * \beta$ for $\sigma_{\mathrm{T}}=2$; variation of $h, U, z_{0}$, $C_{0}$, and $W_{\mathrm{s}}$

\section{Discussion and conclusions}

We have studied the possible contribution of sedimentinduced buoyancy effects on hydraulic drag reduction in open channel flow by applying the log-linear velocity profile proposed by Barenblatt (1953). The parameters in this profile were established through a large number of numerical experiments with the 1DV POINT MODEL. In this model, we apply a Prandtl-Schmidt number $\sigma_{\mathrm{T}}=0.7$ for neutral conditions. In Appendix 2, we repeat Uittenbogaard's (1995a) arguments that in homogeneous flows $\sigma_{\mathrm{T}}$ should indeed be smaller than unity. In stratified, one-phase fluids, as encountered in the ocean, estuaries, and the atmosphere, $\sigma_{\mathrm{T}}$ increases with stratification, as momentum can be transported against the buoyancy forces by internal waves, generated in such fluids. However, these waves cannot transport matter (i.e., denser or lighter fluid). In case of twophase fluids, such as sediment-laden flows, $\sigma_{\mathrm{T}}$ is expected to increase even more, as breakdown of stratification by vertical mixing would be restored rapidly by the falling sediment particles. Though many formulae exist in literature relating $\sigma_{\mathrm{T}}$ with the Richardson number, no consensus exists, in particular not for sediment-laden flow. Therefore, we prefer to apply a constant Prandtl-Schmidt number in the current study. From calibration of the 1DV POINT MODEL against laboratory and flume data, we concluded that credible results are obtained for $\sigma_{\mathrm{T}}=2$ for the current model implementation. We believe further research is required, based on further field data, which are not really available at present, to substantiate the $\sigma_{\mathrm{T}}$ choice in more detail.

A common length scale to describe vertical mixing in stratified conditions is the Monin-Obukhov length scale, derived for atmospheric conditions. However, in open channel flow, vertical mixing is also limited by the presence of the free water surface. Therefore, we propose to extend the classical Barenblatt profile to a log-parabolic profile with a term representing the effects of the free water surface by including a second reference length scale, further to the Monin-Obukhov length scale. One candidate for this length scale is the Ekman depth, as this limits vertical mixing in open water systems. However, through the procedure applied in this paper, this reference scale is inherently included in the coefficients obtained.

Inspection of the classical log-linear velocity profile by Barenblatt and the newly proposed log-parabolic profile shows that sediment-induced drag reduction is unlikely to be observed in laboratory conditions, as the vertical scale $(z)$ in the linear/parabolic part of the profiles will never attain values comparable to its logarithmic part.

Our results suggest a relation for the effective Chézy coefficient in sediment-laden open water flows given by Eq. (5) for a variety in environmental parameters (i.e., $0.5<$ $h<20 \mathrm{~m} ; 0.5<U<2 \mathrm{~m} / \mathrm{s} ; 0.05<z_{0}<1 \mathrm{~mm} ; 0.05<W_{\mathrm{s}}<5 \mathrm{~mm} / \mathrm{s}$; $\beta<<1$ ) typical for open channel flow. With these settings, we predict drag reductions up to $30 \%$, consistent with observations in the field.

However, we did not study the effects of other dragreducing mechanisms, such as thickening of the viscous sub-layer, vanishing bed forms, or the role of fluid mud layers. In particular, the latter can be pronounced. Though the 1DV POINT MODEL predicts large drag reductions upon the collapse of the turbulence field and subsequent formation of fluid mud, the computed values are unreliable, as the turbulence model in the 1DV POINT MODEL is not suitable to accurately assess turbulent stresses under fluid mud conditions.

As discussed in the introduction to this paper, drag reduction has been observed frequently in many rivers laden with high-concentrated mud suspensions. When the domain of influence is large, this drag reduction may even lead to significant changes in the characteristics of the tidal propagation, even further augmenting the feedback between suspended sediments and water movement. Basically, the effects of sediments on the effective hydraulic roughness through buoyancy destruction should be accounted for implicitly in fully coupled, three-dimensional numerical models, i.e., including a feedback between suspended sediment, effective fluid density, and turbulent mixing. The use of such models may be prohibitive in some cases, in particular for large-scale applications, and a depth-averaged approach may be more feasible. In that case, the effective roughness coefficient can be assessed with Eq. (5), using proxies for the bulk Richardson number and Rouse number.

We note that the current analysis is applicable to fine suspended sediment which is mixed up to the water surface, i.e., when $\beta<<1$. If not, the mathematical analysis in the appendix does not hold anymore. Yet, it is likely that said effects also occur for courser material-the key issue is whether vertical gradients in suspended sediment cause sufficient damping in vertical mixing, reducing the effective 
hydraulic drag. However, we have not treated the effects of courser material; this is subject of further research.

Our new formula (5) can easily be extended to include the effects of vertically homogeneous horizontal salinity gradients $\mathrm{d} S / \mathrm{d} x$, responsible for gravitational circulation. For this purpose, we use the derivations presented in Winterwerp et al. (2006), yielding:

$$
\begin{aligned}
\frac{\bar{u}}{u_{*}} \equiv \frac{C_{\mathrm{eff}}}{\sqrt{g}} & =\frac{C_{0}}{\sqrt{g}}+\frac{C_{\mathrm{SPM}}}{\sqrt{g}}+\frac{C_{\mathrm{SAL}}}{\sqrt{g}} \\
& =\frac{C_{0}}{\sqrt{g}}+4 h R i_{*} \beta+\frac{1}{4 \kappa} R i_{x}
\end{aligned}
$$

in which $R i_{x}$ is the horizontal Richardson number, defined as $R i_{x}=\left(\alpha g h^{2} / \rho u_{*}^{2}\right) \mathrm{d} S / \mathrm{d} x$, where $\rho=\rho_{\mathrm{f}}+\alpha S(\alpha \approx 0.8)$, and $\rho_{\mathrm{f}}$ is fresh water density. It would not be difficult, from a mathematical point of view, to include the effects of vertical stratification in the salinity distribution as well. However, from a physical point of view, this is not very useful. Salinity effects are limited to a few $10 \mathrm{~km}$ at most, i.e., the salinity intrusion part of the estuary, whereas the effect of sediment may be relevant over much longer trajectories. In other words, salinity-induced drag reduction may have a local effect, but its effect on the overall propagation of the tidal wave is much smaller than may be induced by suspended fine sediments.

Acknowledgments This work has been carried out as part of the project "Predictive Morphological Modeling of the Lower Yellow River", financed by the Dutch Royal Academy of Sciences (KNAW) and the Chinese Ministry of Science and Technology within the framework of the Program of Scientific Alliances between China and the Netherlands. We also would like to acknowledge the work of two unknown reviewers, who commented our paper in detail.

Open Access This article is distributed under the terms of the Creative Commons Attribution Noncommercial License which permits any noncommercial use, distribution, and reproduction in any medium, provided the original author(s) and source are credited.

\section{Appendix 1-integration of the log-parabolic profile}

Further elaboration of the second term of Eq. (2), substituting the Monin-Obukhov length scale and assuming local equilibrium, yields:

$$
\begin{aligned}
\int_{0}^{h} \mathrm{dz}\left\{\alpha_{1} \frac{\kappa g\left(\rho_{\mathrm{b}}-\rho_{\mathrm{w}}\right)}{\rho_{\mathrm{b}} u_{*}^{3}} \overline{w^{\prime} c^{\prime}} z \frac{z}{z_{0}} \frac{z}{h_{\mathrm{ref}}}\right\} \\
=\int_{0}^{h} \mathrm{~d} z\left\{\alpha_{1} \frac{\kappa g\left(\rho_{\mathrm{b}}-\rho_{\mathrm{w}}\right)}{\rho_{\mathrm{b}} u_{*}^{3}} W_{\mathrm{s}} c z \frac{z}{z_{0}} \frac{z}{h_{\mathrm{ref}}}\right\}
\end{aligned}
$$

For $\beta<<1$, integration of the vertical sediment balance equation $w_{\mathrm{s}} c=\Gamma_{\mathrm{T}} \mathrm{d} c / \mathrm{d} z$, assuming a parabolic eddy diffusivity profile $\Gamma_{\mathrm{T}}$, the relation between concentration $c$ $(z)$ and its depth-averaged value $\bar{c}$ reads (Winterwerp and Van Kesteren 2004):

$c(z)=\bar{c} \frac{\sin \{\pi \beta\}}{\pi \beta}\left(\frac{1-z / h}{z / h}\right)^{\beta}$ for $\beta<<1$

where $\beta=\sigma_{\mathrm{T}} W_{\mathrm{s}} / \kappa u_{*}$ is the Rouse number. Hence, integration of Eq. (7) yields:

$$
\begin{gathered}
\int_{0}^{h} \alpha_{1} \frac{\kappa g\left(\rho_{\mathrm{b}}-\rho_{\mathrm{w}}\right)}{\rho_{\mathrm{b}} u_{*}^{3}} W_{\mathrm{s}} c z^{2} \mathrm{~d} z \approx K_{1} h \frac{\kappa g\left(\rho_{\mathrm{b}}-\rho_{\mathrm{w}}\right)}{\rho_{\mathrm{b}} u_{*}^{3}} W_{\mathrm{s}} h \bar{c}= \\
=K_{1} h \frac{g h\left(\rho_{\mathrm{b}}-\rho_{\mathrm{w}}\right)}{\rho_{\mathrm{b}} u_{*}^{2}} \frac{\sigma_{\mathrm{T}} W_{\mathrm{s}}}{\kappa u_{*}}=K_{1} h R i_{*} \beta
\end{gathered}
$$

where $K_{1}$ is an empirical/numerical coefficient to be determined, $\bar{c}=$ depth-averaged concentration and $R i_{*}$ is the bulk Richardson number, defined as $R i_{*}=$ $\left(\rho_{\mathrm{b}}-\rho_{\mathrm{w}}\right) g h / \rho_{\mathrm{b}} u_{*}^{2}$, with $\rho_{\mathrm{b}}=$ bulk density of sedimentladen flow.

\section{Appendix 2-the 1DV POINT MODEL}

The transport of fine-grained sediment in estuaries and coastal waters is described with the continuity equation for the water phase, the momentum equation, the mass balance equation for the suspended sediment, a turbulence closure model, an equation of state, relating fluid density and suspended sediment concentration (and water temperature and salinity), and appropriate boundary conditions. As this paper focuses on the processes in the vertical, the three-dimensional equations are simplified to one (vertical) dimension only. These equations are implemented in the 1DV POINT MODEL. This model is based on Delft Hydraulics' full three-dimensional hydrostatic code Delft3D, but in which all horizontal gradients have been stripped, except for the longitudinal pressure gradient. The horizontal momentum equation in the 1DV POINT MODEL reads:

$\frac{\partial u}{\partial t}+\frac{1}{\rho} \frac{\partial p}{\partial x}=\frac{\partial}{\partial z}\left\{\left(v+v_{\mathrm{T}}\right) \frac{\partial u}{\partial z}\right\}-\frac{1}{\rho} \frac{2 \tau_{\mathrm{sf}}}{b}$

in which $p$ is the pressure, $u(z, t)$ is the horizontal flow velocity, $x$ and $z$ are the horizontal and vertical coordinates, $t$ is time, $\rho$ is the fluid bulk density, $\nu$ is the kinematic viscosity, $\nu_{\mathrm{T}}(z, t)$ is the eddy viscosity, including the possible effects of wind and/or waves, $\tau_{\text {sf }}$ the possible wall shear stress, and $b$ the width of the channel. The pressure term in 
Eq. (10) is adjusted to maintain a given time-varying depthaveraged flow velocity:

$$
\begin{aligned}
\frac{1}{\rho} \frac{\partial p}{\partial x} & =\frac{\tau_{\mathrm{s}}-\tau_{\mathrm{b}}}{\rho h}-\frac{2 \tau_{\mathrm{sf}}}{\rho b}+\frac{U(t)-U_{0}(t)}{T_{\text {rel }}}, \\
U(t) & =\frac{1}{h} \int_{z_{\mathrm{bc}}}^{\zeta} u(z, t) \mathrm{d} z
\end{aligned}
$$

where $h$ is the water depth, $U$ is the actual computed depthaveraged flow velocity, $U_{0}$ is the desired depth-averaged flow velocity, $T_{\text {rel }}$ is a relaxation time, $z_{\mathrm{bc}}$ is the apparent roughness height, $\tau_{\mathrm{b}}$ is the bed shear stress, $\tau_{\mathrm{s}}$ is a possible surface shear stress, and $\zeta$ is the surface elevation. A quadratic friction satisfying the log-law is used, and the boundary conditions to Eq. (10) read:

$$
\tau_{\mathrm{b}}=\left.\left\{\rho\left(v+v_{\mathrm{T}}\right) \frac{\partial u}{\partial z}\right\}\right|_{z=z_{\mathrm{bc}}} ; \quad \tau_{\mathrm{s}}=\left.\left\{\rho\left(v+v_{\mathrm{T}}\right) \frac{\partial u}{\partial z}\right\}\right|_{z=\zeta}
$$

For hydraulically rough conditions, the apparent roughness height is prescribed at the bed, whereas for hydraulically smooth conditions the friction coefficient is determined as a function of the flow Reynolds number by the Kármàn-Schoenherr equation.

We apply the $k-\varepsilon$ turbulence model for sediment-laden turbulent flow. Its standard version (e.g., Rodi 1984) is implemented in the 1DV POINT MODEL; it consists of transport equations for the turbulent kinetic energy $k$ and the turbulent dissipation $\varepsilon$, neglecting horizontal transport components:

$$
\frac{\partial k}{\partial t}=\frac{\partial}{\partial z}\left\{\left(v+\Gamma_{T}^{(k)}\right) \frac{\partial k}{\partial z}\right\}-\overline{u^{\prime} w^{\prime}} \frac{\partial u}{\partial z}-\frac{g}{\rho} \overline{\rho^{\prime} w^{\prime}}-\varepsilon
$$

$$
\begin{aligned}
\frac{\partial \varepsilon}{\partial t}= & \frac{\partial}{\partial z}\left\{\left(v+\Gamma_{T}^{(\varepsilon)}\right) \frac{\partial \varepsilon}{\partial z}\right\}-c_{1 \varepsilon} \frac{\varepsilon}{k} \overline{u^{\prime} w^{\prime}} \frac{\partial u}{\partial z} \\
& -\left(1-c_{3 \varepsilon}\right) \frac{\varepsilon}{k} \frac{g}{\rho} \overline{\rho^{\prime} w^{\prime}}-c_{2 \varepsilon} \frac{\varepsilon^{2}}{k}
\end{aligned}
$$

in which a prime denotes turbulent fluctuations and an overbar averaging over the turbulent time scale. The turbulent transport terms are modeled as a diffusion process, and the eddy viscosity $\nu_{\mathrm{T}}$ and eddy diffusivity $\Gamma_{\mathrm{T}}^{(\varphi)}$ are given by:

$v_{\mathrm{T}}=c_{\mu} \frac{k^{2}}{\varepsilon} ; \quad \Gamma_{\mathrm{T}}^{(\varphi)}=\frac{v_{\mathrm{T}}}{\sigma_{\mathrm{T}}^{(\varphi)}}$

in which $\sigma_{\mathrm{T}}{ }^{(\varphi)}$ is the turbulent Prandtl-Schmidt number for substance $\varphi$. Most coefficients in the $k-\varepsilon$ turbulence model are well established and are the result of calibration against grid-generated turbulence and a log-law velocity profile for homogeneous flow.

The values of the Prandtl-Schmidt number $\sigma_{\mathrm{T}}$ and the coefficient $c_{3 \varepsilon}$ are less well established. Here, Uittenbogaard (1995a) is followed. He showed conclusively that in free turbulence, $\sigma_{\mathrm{T}}=0.7$, even under highly stratified conditions. Experimental data deviating from this value are explained in terms of the effects of internal waves, which do transfer momentum, but not mass. This effect is generally accounted for by a modification of $\sigma_{\mathrm{T}}$, which is often modeled as a function of the Richardson number itself. One of the first models accounting for the effects of stratification on the Prandtl-Schmidt number is by Munk and Anderson (1948). Their work was continued by many researchers, and more recent models can be found in Toorman (2008) and Burchard (2002). The main conclusion of these studies is that $\sigma_{\mathrm{T}}$ rapidly increases with increasing stratification, e.g., Richardson number. However, it is noted that all these studies have been based on data on one-phase fluids and gases (i.e., stratification in water by salinity and/or heat, c.q. in the atmosphere). Van Rijn (1987, 1993) gives some data on two-phase fluids (e.g., fine sediment suspensions), but derives the same conclusion that $\sigma_{\mathrm{T}}$ increases with Richardson number, except for fairly heavy particles.

Uittenbogaard $(1995 \mathrm{a}, \mathrm{b})$ instead promotes the use of additional terms in the $k-\varepsilon$ model through which the effects of internal waves can be described explicitly. $\mathrm{He}$ also argued why $\sigma_{\mathrm{T}}<1$ for neutral conditions. In turbulent flow, packages of fluid are deformed continuously by the turbulent stresses in the fluid. The deformation of these packages, however, is restricted by the requirements of continuity: if the deformation in two directions is given at any instant, then the deformation in the third direction follows from continuity. In other words, if $\partial u_{1}^{\prime} / \partial x_{1}$ and $\partial u_{2}^{\prime} / \partial x_{2}$ are given, $\partial u_{3}^{\prime} / \partial x_{3}$ is set. This affects the value of the correlation between the turbulent velocity components. This restriction does not apply to a solute, as a solute can diffuse freely through the fluid. Hence, the correlation between $c^{\prime}$ and $u_{1}^{\prime}$ has more degrees of freedom than the correlation between the turbulent velocity components themselves. It can be shown that the particles of finegrained sediment can be treated as a passive tracer (apart from its settling velocity) in a single-phase description, the argument above is also valid for the turbulent diffusion of the fine sediments in the present study.

From an analysis of the experiments in stratified flow by Lienhard and Van Atta (1990), Uittenbogaard (1995a) also concluded that for stable stratified flows, the buoyancy term in the $\varepsilon$-equation vanishes $\left(c_{3 \varepsilon}=1\right)$. For unstable stratified flow conditions $c_{3 \varepsilon}=0$ is fair, which implies $\varepsilon$-production, i.e., small-scale turbulence production, by Rayleigh-Taylor instabilities.This analysis yields the following set of 
coefficients in the $k-\varepsilon$ model:

$c_{\mu}=0.09, c_{1 \varepsilon}=1.44, c_{2 \varepsilon}=1.92, \sigma_{\mathrm{T}}^{(k)}=1.0, \sigma_{\mathrm{T}}^{(\varepsilon)}=1.3$,

$\sigma_{\mathrm{T}}^{(\rho)}=0.7, \kappa=0.41, c_{3 \varepsilon}=1$ for stable stratification

The $k-\varepsilon$ model is closed with the following set of boundary conditions:

$\left.k\right|_{z=z_{\mathrm{bc}}}=\frac{u_{*_{\mathrm{b}}}^{2}}{\sqrt{c_{\mu}}},\left.\quad \varepsilon\right|_{z=z_{\mathrm{bc}}}=\frac{u_{*_{\mathrm{b}}}^{3}}{\kappa z_{\mathrm{bc}}},\left.\quad k\right|_{z=\zeta}=0,\left.\quad \varepsilon\right|_{z=\zeta}=0$

The transport of sediment is modeled with the advectiondiffusion equation:

$\frac{\partial c}{\partial t}-\frac{\partial}{\partial z}\left\{W_{\mathrm{s}, \mathrm{ef}} c\right\}-\frac{\partial}{\partial z}\left\{\left(D+\Gamma_{\mathrm{T}}\right) \frac{\partial c}{\partial z}\right\}=0, \quad$ with

$W_{\mathrm{s}, \mathrm{ef}}=W_{\mathrm{s}, \mathrm{o}}(1-\phi)^{\beta}$ to account for hindered settling

in which $W_{\mathrm{s}, \mathrm{o}}$ is the settling velocity of a single grain in still water and the exponent $\beta$ generally has the value $\beta \approx 5$ for fine-grained sediment. The volume concentration $\phi$ in Eq. (17) is related to the mass concentration $c$ through $\phi=c / \rho_{\text {ref }}$, where $\rho_{\text {ref }}$ is either the density of massive sand particles (i.e., $\rho_{\text {ref }}=\rho_{\mathrm{s}} \approx 2,650 \mathrm{~kg} / \mathrm{m}^{3}$ ), or, in case of muddy suspensions, the gelling concentration $\rho_{\text {ref }}=c_{\text {gel }}$, i.e., the sediment concentration at which a space-filling network is formed as a result of flocculation processes.

The boundary condition at the bed is given by a zero sediment flux, or prescribed either by the classical KronePartheniades formulae for cohesive sediment, or by the formula of Van Rijn (1987) for non-cohesives. At the water surface, a zero-flux boundary condition is prescribed. The buoyancy term in Eqs. (13) and (14) accounts for the effect of vertical sediment and salinity gradients through the equation of state:

$\rho(S, c)=\rho_{\mathrm{w}}(S)+\left(1-\frac{\rho_{\mathrm{w}}(S)}{\rho_{\mathrm{s}}}\right) c$

with $\rho_{\mathrm{w}}(S)$ the density of the water due to salinity only. These equations are solved on a so-called $\sigma$-coordinate system. Time discretization is based on the $\theta$-method; for $\theta=1$ the Euler-implicit time integration method is obtained. The convection term is discretized by a first-order upwind scheme in conjunction with a three-point scheme for the diffusion operator. Details on the implementation of the $k-\varepsilon$ model are given by Stelling (1995). The $k-\varepsilon$ implementation was validated against a number of experiments, as reported by Stelling (1995). Recently, De Boer (2009) compared the turbulence model implementation with data on dissipation rates by Rippeth et al. (2001), showing a good agreement between model and data. The 1DV POINT MODEL is validated, amongst other things, against analytical solutions of the vertical sediment concentration profile provided by Malcherek (1995), which results are not repeated here, and against measured vertical velocity and concentration profiles for sediment-laden flow in a straight flume as published by Coleman (1981), as shown in Winterwerp (2001).

\section{References}

Barenblatt GF (1953) On the motion of suspended particles in a turbulent stream. Prikladnaja Matematika i Mekhanika 17:261274 English translation

Beardsley RC, Candela J, Limeburner R, Geyer WR, Lentz SJ, Castro BM, Cacchione D, Carneiro $\mathrm{N}$ (1995) The $\mathrm{M}_{2}$ tide on the Amazon shelf. J Geophys Res 100:2283-2319

Burchard H (2002) Applied turbulence modelling in marine waters. Springer, Germany

Burchard H, Baumert H (1995) On the performance of a mixed-layer model based on the $k-\varepsilon$ turbulence closure. J Geophys Res 100 (C5):8523-8540

Cellino M, Graf WH (1999) Sediment-laden flow in open channels under non-capacity and capacity conditions. ASCE, J Hydraulic Eng 125(5):456-462

Coleman NL (1981) Velocity profiles with suspended sediment. J Hydraul Res 19(3):211-229

De Boer GJ (2009) On the interaction between tides and stratification in the Rhine region of freshwater influence. PhD thesis, Delft University of Technology

Delft Hydraulics Laboratory (1974) Momentum and mass transfer in stratified flows. Report R880

Dong L, Wolanski E, Li Y (1997) Field and modelling studies of fine sediment dynamics in the extremely turbid Jiaojianng River estuary, China. J Coastal Res 13(4):995-1003

Dyer KR (1997) Estuaries: a physical introduction. Wiley, Chichester

Gabioux M, Vinzon SB, Paiva AM (2005) Tidal propagation over fluid mud layers on the Amazon shelf. Cont Shelf Res 25:113125

Guan WB, Wolanski E, Dong LX (1998) Cohesive sediment transport in the Jiaojiang River Estuary, China. Estuar Coast Shelf Sci $46: 861-871$

Gust G (1976) Observations on turbulent-drag reduction in a dilute suspension of clay in sea water. J Fluid Mech 75(1):29-47

Le Hir P (1994) Mathematical modeling of cohesive sediment and particulate contaminants transport in the Loire Estuary, In: Bolsen T, Fredensborg O (eds), Denmark, pp 71-78

Le Hir P, Cayocca F (2002) 3D application of the continuous modeling concept to mud slides in open seas. In: Winterwerp JC, Kranenburg C (eds) Fine sediment dynamics in the marine environment, Elsevier, Proceedings in Marine Sciences 5:545-562

Lienhard JH, Van Atta CW (1990) The decay of turbulence in thermally stratified flow. J Fluid Mech 210:57-112

Lumley JL (1969) Drag reduction by additives. In: Sears WR, van Dyke M (eds) Annual review of fluid mechanics, vol 1, pp 367-383

Malcherek A (1995) Mathematische Modellierung von Strömungen und Stofftransportprozessen in Ästuaren. Dissertation, Institut für Strömungsmechanik und Elektronisch Rechnen im Bauwesen der Universität Hannover, Bericht Nr. 44/1995 (in German)

Munk WH, Anderson ER (1948) Notes on a theory of the thermocline. J Mar Res 7:276-295 
Odd NVM, Cooper AJ (1988) A two-dimensional model of the movement of fluid mud in a high energy, INTERCOH-1988. In: Mehta AJ, Hayter EJ (eds) 1989. High concentration cohesive sediment transport, Journal of Coastal Research, Special Issue No. 5, Summer 1989, 185-194

Port and Delta Consortium Ltd, July 1995. Regulation of the Yangtze Estuary, Volume B: Hydro-morphological assessment and mathematical models, Part 1: Description. Delft, The Netherlands.

Rippeth TP, Fischer NR, Simpson JS (2001) The cycle of turbulent dissipation in the presence of tidal straining. J Phys Oceanogr 31 (8):2458-2471

Rodi, W., 1984. Turbulence models and their applications in hydraulics - a state-of-the-art review. IAHR monograph, Delft, The Netherlands.

Soulsby RL, Wainwright BLSA (1987) A criterion for the effect of suspended sediment on near-bottom velocity profiles. J Hydraul Res 25(3):341-356

Stelling GS (1995) Compact differencing for stratified surface flow. In: Advances in Hydro-Science and -Engineering, II (A) 378386, Tsinghua University Press, Beijing, China

Toorman EA (2008) Vertical mixing in the fully developed turbulent layer of sediment-laden open-channel flow. ASCE, J Hydraulic Eng 134(9):1225-1235

Turner JS (1973) Buoyancy effects in fluids. Cambridge University Press, Cambridge

Uittenbogaard RE (1995a) The importance of internal waves for mixing in a stratified estuarine tidal flow. PhD thesis, Delft University of Technology, September 1995

Uittenbogaard RE (1995b) Observations and analysis of random internal waves and the state of turbulence. Proceedings of the
IUTAM symposium on Physical Limnology, Broome, Western Australia, September 10-14, 1995

Van Rijn LC (1987) Mathematical modelling of morphological processes in the case of suspended sediment transport. $\mathrm{PhD}$ thesis, Delft University of Technology, Faculty of Civil Engineering

Van Rijn LC (1993) Principles of sediment transport in rivers, estuaries and coastal seas. AQUA, Blokzijl

Wang ZY, Larsen P, Nestmann F, Dittrich A (1998) Resistance and drag reduction of flows of clay suspensions. ASCE, J Hydraulic Eng 124(1):41-49

Weilbeer H (2005) Numerical simulation and analysis of sediment transport processes in the Ems-Dollard estuary with a three-dimensional model. In: Kusuda T, Yamanishi H, Spearman J, Gailani JZ (eds) Sediment and ecohydraulics, INTERCOH 2005. Elsevier, Proceedings in Marine Science, pp 447-462

Winterwerp JC (2001) Stratification of mud suspensions by buoyancy and flocculation effects. J Geophys Res 106(10):22,559-22,574

Winterwerp JC, Van Kesteren WGM (2004) Introduction to the physics of cohesive sediment in the marine environment. Elsevier, Developments in Sedimentology, p 56

Winterwerp JC (2006) Stratification effects by fine suspended sediment at low, medium and very high concentrations. Geophys Res 111(C05012):1-11

Winterwerp JC, Wang ZB, Van der Kaaij T, Verelst K, Bijlsma A, Meersschaut Y, Sas M (2006) Flow velocity profiles in the Lower Scheldt estuary. Ocean Dynamics 56:284-294

Xu J (2003) Sedimentation rates in the Lower Yellow River over the past 2300 years as influenced by human activities and climate change. Hydrol Process 17:3359-3371 